\title{
Rapid Prototyping for Biomedical Engineering: Current Capabilities and Challenges
}

\section{Andrés Díaz Lantada and Pilar Lafont Morgado}

\section{Keywords}

rapid manufacturing, biomedical devices, tissue engineering, organ printing, biofabrication

\begin{abstract}
A new set of manufacturing technologies has emerged in the past decades to address market requirements in a customized way and to provide support for research tasks that require prototypes. These new techniques and technologies are usually referred to as rapid prototyping and manufacturing technologies, and they allow prototypes to be produced in a wide range of materials with remarkable precision in a couple of hours. Although they have been rapidly incorporated into product development methodologies, they are still under development, and their applications in bioengineering are continuously evolving. Rapid prototyping and manufacturing technologies can be of assistance in every stage of the development process of novel biodevices, to address various problems that can arise in the devices' interactions with biological systems and the fact that the design decisions must be tested carefully. This review focuses on the main fields of application for rapid prototyping in biomedical engineering and health sciences, as well as on the most remarkable challenges and research trends.
\end{abstract}




\section{Contents}

\section{PRODUCT DEVELOPMENT AND RAPID}

PROTOTYPING TECHNOLOGIES $\ldots \ldots \ldots \ldots \ldots \ldots \ldots \ldots \ldots \ldots \ldots \ldots . \ldots \ldots$

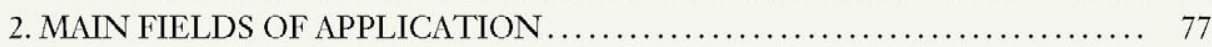

2.1. Biomodels and Prototypes for Diagnosis ......................... 77

2.2. Biomodels for Surgical Training, Planning, and Procedures............. 78

2.3. Direct Manufacture of Implantable Devices for Hard-Tissue Replacement ... . 78

2.4. Direct Manufacture of Implantable Devices for Soft-Tissue Replacement .... . 79

2.5. Direct Manufacture of Orthotic Devices for Performance Enhancement ..... 79

2.6. Direct Manufacture of Biodevices Based on Intelligent Materials.......... 80

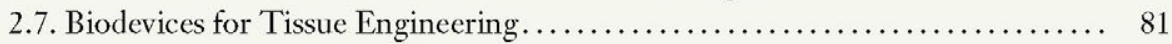

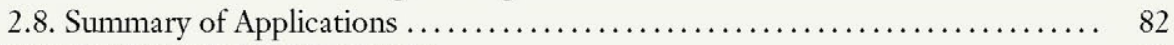

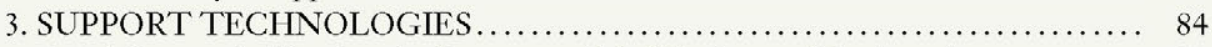

3.1. Advances in Biomimetic Computer-Aided Design and Engineering ......... 84

3.2. Imaging and Imaging-Based Design Technologies .................. 85

3.3. Novel Micro-Rapid Prototyping Technologies for Advanced Biomaterials .... 85

3.4. Nanomanufacturing for Interacting at a Molecular Scale............... 86

4. MAIN CHALLENGES AND FUTURE PROPOSALS ................... 88

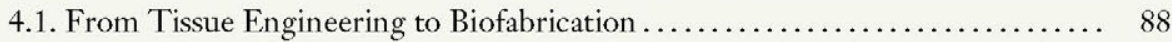

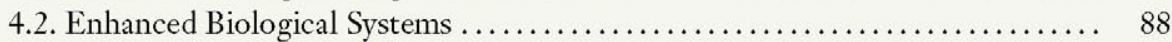

4.3. Food, Pharmaceuticals, and Sustainable Growth .................... 89

4.4. The Need for Collaboration Among Researchers.................... 89

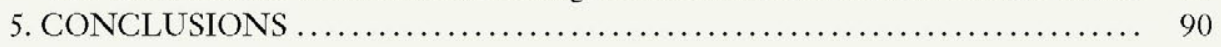

\section{PRODUCT DEVELOPMENT AND RAPID PROTOTYPING TECHNOLOGIES}

Rapid prototyping and manufacturing technologies allow researchers to generate physical parts in a short period (hours or days), directly from designs created via computer-aided design (CAD), computer-aided engineering (CAE), and computer-aided manufacturing (CAM) programs (see Figure 1). Such technologies significantly help optimize design iterations, allowing for the early detection of errors and speeding up the whole development process. They are generally based on automatic, additive, layer-by-layer manufacturing processes (also referred as layer manufacturing technologies). In some cases, fast manufacturing processes that involve material removal, such as high-speed numerical control machining, are also included within the concept of rapid prototyping, although the term usually describes additive processes. The various technologies available can operate and manufacture - with outstanding precision - prototypes that incorporate a wide range of metals, ceramics, or polymers and those that can have either a synthetic or biological origin $(1,2)$.

Remarkable technologies (and associated materials) that have a significant impact on the evolution of the rapid prototyping industry include laser stereolithography (photosensitive polymers), selective laser sintering (polymer powder, usually nylon or ceramic powder), 3D printing (powder with binder or liquid resins), or fused deposition modeling (thermoplastics). All of these are based on deposition processes or layered manufacturing, which facilitate the creation of complex geometries, including inner details, carried out directly from the associated CAD files. Several design guidelines and user forums provide additional information on 


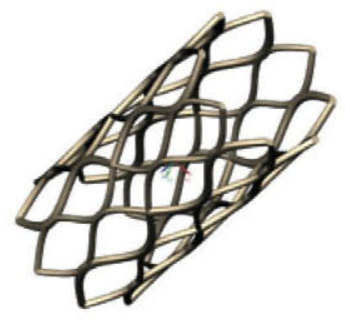

Example: Stent design produced with help of CAD software

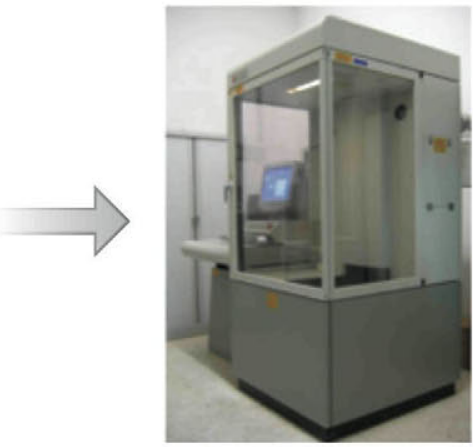

Conversion to .stl format/polyhedrization, introduction of CAD file in RP machine

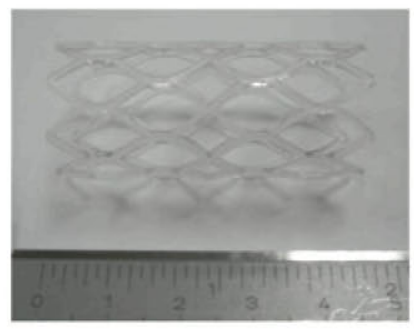

Automatic layer-by-layer prototype manufactured according to the CAD geometry

Figure 1

Schematic description of the rapid prototyping (RP) process using the SLA ${ }^{\circledR} 3500$ laser stereolithography system from 3D Systems, Inc. Abbreviations: CAD, computer-aided design; stl, standard tessellation language.

conventional rapid prototyping technologies (1; see also http://www.prototypezone.com/ and http://www.crptechnology.com/sito/en.html).

Other, more recent technologies offer an optimized precision of a few micrometers or even hundreds of nanometers. Because of this precision, these technologies are specifically applicable to biomedical engineering; for example, they can help in manufacturing implantable devices or scaffolds for tissue engineering processes. These technologies are analyzed and compared in detail in Section 3.3.

Technologies known as rapid tooling technologies within rapid manufacturing are also noteworthy, as they can produce tools and parts for injection molds quickly and economically, by reproducing the geometry of physical models, by using shape-copying processes, or by directly manufacturing such tools and parts in an additive way through rapid prototyping processes. However, rapid tooling technologies are not frequently applied to biomedical engineering, as they are more oriented toward small-series and preseries production. In biomedical engineering, solutions are often customized to suit patients, so a single prototype usually suffices.

Almost all departments involved in the process of launching a new product benefit from the systematic use of these rapid prototyping technologies. A previous prototype is a physical communication tool that reduces the risk of possible misinterpretation, which may occur if only CAD designs or plans are used, and allows subjective features (aesthetics, ergonomics) to be analyzed. Rapid prototyping technologies can also be used to perform tests of assembly and interference in order to check the designs. In addition, functional prototypes can also be produced to verify the performance of parts and products, although sometimes with certain mechanical limitations, depending on the materials and technologies used. They dramatically improve the relationship between customers and suppliers and often help promote improvements in both the design and production processes. Furthermore, owing to the development of new combinations of technologies and materials, rapid prototyping technologies and the prototypes they generate allow for customized approaches, which are of great interest to the biomedical industry (see below).

Figures 2 and 3 show the results of a search performed using Thomson Reuters's Web of Knowledge ${ }^{\mathrm{SM}}$ database in January 2011, including data on the numbers of scientific papers and patents related to rapid prototyping technologies (Figure 2) and information on the key areas of application (Figure 3). Statistics relating to publications (taken from the Science Citation Index) 


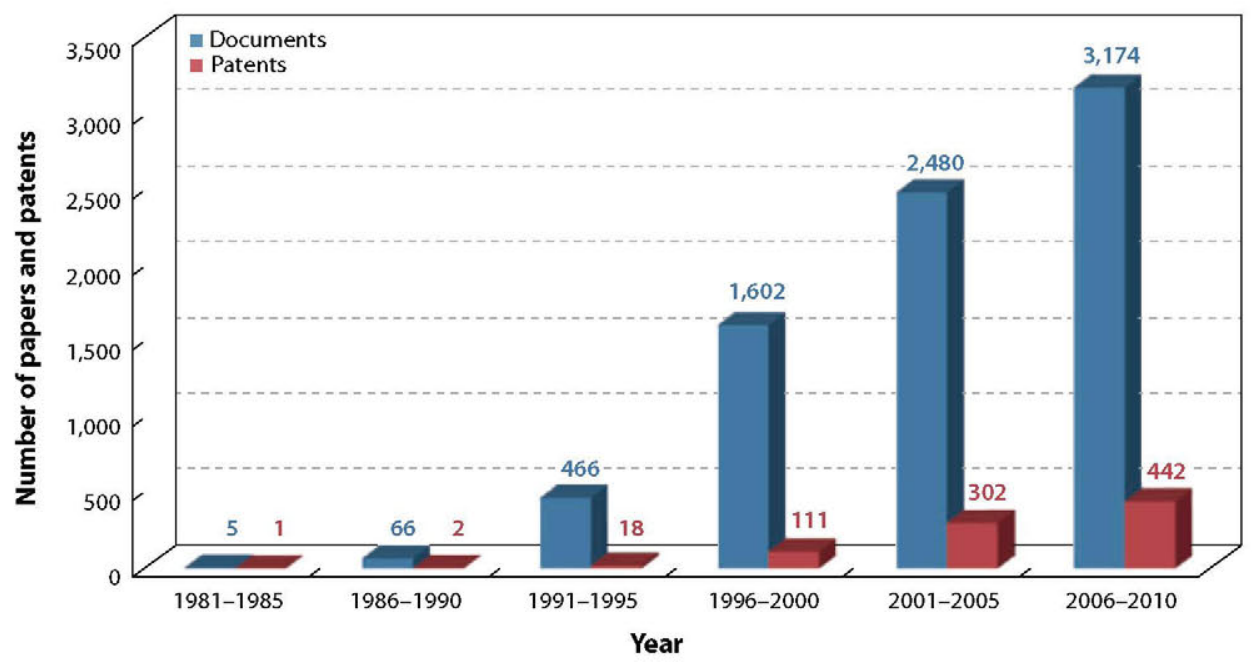

Figure 2

Trends in the number of scientific papers and patents related to the subjects of rapid prototyping and rapid manufacturing over the past three decades. Data from Thomson Reuters's Web of Knowledge ${ }^{\mathrm{SM}}$ database, January 2011.

show the scientific impact of studies in rapid prototyping, whereas the data on patents (taken from the Derwent Innovations Index) are more linked to the technological transfer to society and to their industrial success.

Searches using the character string "rapid prototyping" or "rapid manufacturing" yielded 7793 papers and 876 patents covering the period from the early 1980s to the end of 2010 (Figures 2 and 3). It is possible that papers referring to the brand names of the rapid manufacturing technologies

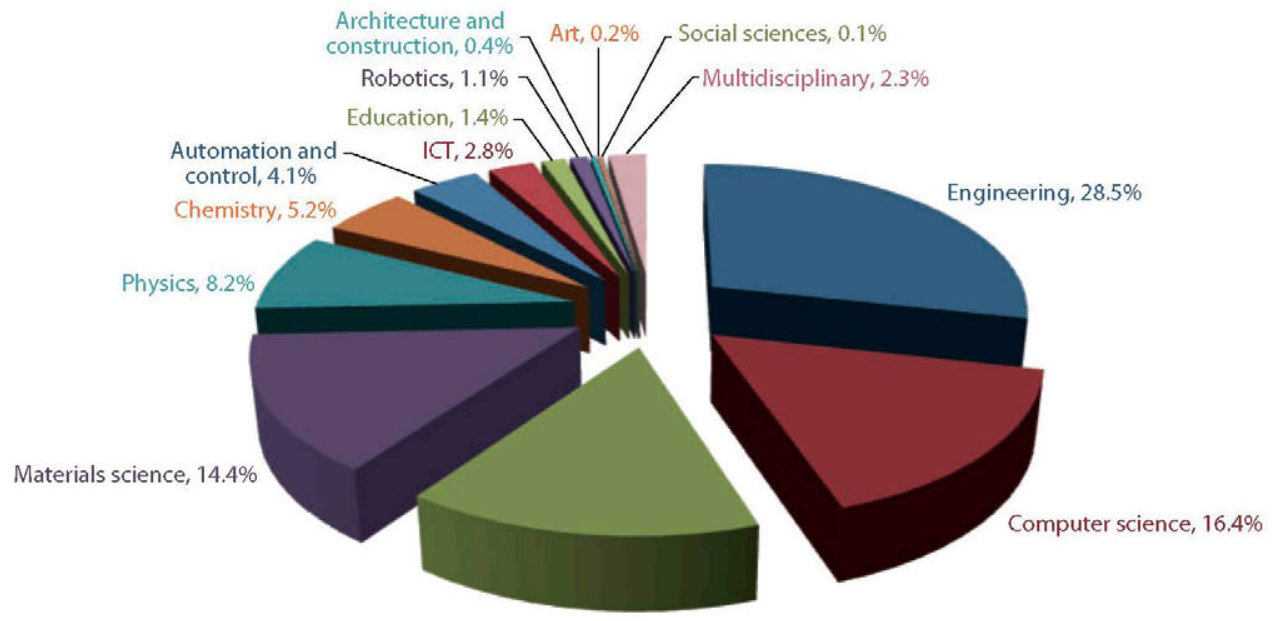

Biomedical engineering, $15.0 \%$

Figure 3

The main fields of application for rapid prototyping technology. Data from Thomson Reuters's Web of Knowledge ${ }^{S M}$ database, January 2011. Abbreviation: ICT, information and communication technologies. 
rather than the aforementioned search terms might have been excluded from the search results. Nevertheless, we believe that the size of the sample is sufficiently significant.

Regarding scientific papers, we can appreciate a major increase since the early 1990 s, when some key technologies such as laser stereolithography and selective laser sintering began to be commercialized, usually for research centers, universities, and large multinational corporations in the automotive and aeronautics industries. The numbers of patents, which are more related to the industrial impact of these technologies, show a characteristic 5-year delay in growth relative to the numbers of scientific papers published, as papers are more closely linked to areas of research.

One of the main areas of application of rapid prototyping technologies is the field of "traditional" engineering-including mechanical, naval, and aeronautical engineering-which makes up almost $30 \%$ of the papers found (Figure 3). These papers generally describe experiments related to studies of shapes and geometries, stress and strain analysis, design validations, wind-tunnel aerodynamic studies, and ergonomic evaluations, among others.

Papers describing biomedical engineering applications, because of their special importance for this review and because of their strong multidisciplinary nature, were collected separately from those describing traditional engineering applications. Also collected separately were papers describing applications in information and communication technologies, automation, robotics, and architecture, owing to specific connotations arising from their novelty and their connection to numerous other fields, even including art.

After traditional engineering, computer science, biomedical engineering, and materials science represent the three most important fields of application, with rates of related papers at approximately $15 \%$ each. Biomedical engineering has numerous research targets in various different areas in which the use of rapid prototyping presents an increasingly important alternative to more traditional diagnostic and therapeutic solutions. We discuss this in detail (Section 2) and then consider the great potential rapid prototyping may have in the near future, especially in the field of biomedical engineering, owing to remarkable synergies with other technological advances that are currently under way (Section 3). We also discuss current challenges and future research proposals regarding the application of rapid prototyping in biomedical engineering (Section 4).

\section{MAIN FIELDS OF APPLICATION}

\subsection{Biomodels and Prototypes for Diagnosis}

The development of biological and anatomical models was one of the first and most important factors that helped introduce rapid prototyping technologies into the biomedical field. These models are usually customized, according to the patient or field of study, to assist pathology diagnosis and subsequent decisions regarding surgery or pharmaceutical treatment. In many cases, having physical prototypes that reproduce the morphology of patients' internal organs is particularly useful for considering later actions, as the prototypes often provide information that is more valuable and easier to interpret than images produced by conventional medical imaging technologies [e.g., X-ray, computed tomography (CT), nuclear magnetic resonance (NMR), positron emission tomography].

Interesting diagnostic studies have been conducted in various branches of medicine, including general surgery, pneumology (3), maxillofacial surgery (4), traumatology (5), and gynecology (6). In these studies, the use of anatomical models or the implementation of test benches with replicas of organs and tissues-produced using rapid prototyping and manufacturing technologies-has made the tests more realistic and improved the final results. The educational implications of such anatomical models in diagnostic tasks are remarkable, as discussed in Section 4. 
In relation to diagnostic tasks, it is also becoming increasingly crucial to optimize the development and capabilities of lab-on-a-chip devices: microsystems that perform the various functions of a laboratory within a few square centimeters. These devices can be used to analyze blood samples, extract DNA samples, and perform antigen-antibody reactions-in a way that is more rapid, controlled, economical, and cost-effective. Manufacturing lab-on-a-chip devices usually requires obtaining a multitude of microchannels (or even nanochannels), which help manage the distribution of reagents and reaction products. To this end, certain rapid prototyping technologies have already been successfully applied to produce devices made of polymer (7), wax (8), and glass (9). Advances in biomimetic CAD and CAE, together with novel capabilities provided by imaging and imaging-based design technologies (see Sections 3.1 and 3.2), can bring enhanced precision and realism to biomodels for diagnosis.

\subsection{Biomodels for Surgical Training, Planning, and Procedures}

Another area of biomedical engineering in which rapid prototyping technologies are being frequently applied is the production of biological and anatomical models to support surgical training and planning tasks, as well as the development of prototypes to simplify surgical procedures. Groundbreaking research has been done in the production of prototypes for biological models that are used to plan surgical operations in fields as diverse as neurology (10), traumatology (11), and maxillofacial surgery $(12,13)$.

In some cases, rapid customized prototyping supports or complements virtual 3D reconstruction technologies by helping implement physical test benches for surgical training. In other words, training processes using physical models can be combined with virtual training, sometimes with additional help from haptic teleoperators, to create more multidisciplinary training programs and learning methodologies for future surgeons. They may also improve the planning of operations, as described in research relating to the digestive tract (14), heart surgery (15), and maxillofacial surgery (16), for example. The extension of physical models obtained by rapid prototyping to other fields of surgery — especially laparoscopic, arthroscopic, and minimally invasive surgeries - is direct and indeed worthy of study.

World-famous operations relating to the separation of Siamese twins deserve special mention. These operations are highly complex and time-consuming, and proper planning is crucial to minimize the significant risks involved. Examples include an operation performed at the Mattel Children's Hospital at the University of California, Los Angeles, which depended on a close collaboration between the craniofacial surgery team and designers from Biomedical Modeling Inc. (who obtained CAD models of the twins' skulls in .stl format using tomography), as well as the support of InterPRO (which made physical rapid prototypes of the skulls to plan the operation).

As for the rapid manufacture of tools and customized accessories to facilitate surgical procedures, it is worth mentioning experiments related to joint implants (17), dentistry (18), and otorhinolaryngology (19), in which percutaneous procedures are becoming more frequent. In dentistry, customized splints generated by rapid prototyping technologies are starting to be widely used by dentists performing dental implants. These splints, successfully marketed by Materialise NV (Leuven, Belgium), help guide the drill holes made in the jaw or maxilla and help minimize the risk of damage to nerves and adjacent tissues. Advances in medical imaging and related design technologies will help with further developments, as detailed in Section 3.2.

\subsection{Direct Manufacture of Implantable Devices for Hard-Tissue Replacement}

In addition to the development of models for surgical training and planning, the direct manufacture of customized implantable medical devices has been, in the past two decades, another main 
bioengineering area at which rapid prototyping technologies have been aimed. Major experiments have been performed to test their application in numerous surgical procedures, including bone and joint reconstruction $(20,21)$ and cranioplasty or facial reconstruction, usually after traffic accidents $(22,23)$.

In these cases, rapid prototyping technologies such as electrobeam melting and laser fusion are used to directly generate meshes, structural supports, or complete implants made of titanium, titanium alloys, or cobalt-chromium alloys. Also, technologies such as selective laser sintering that work on ceramic materials are employed to produce prototypes with properties similar to those of the bones to be replaced.

However, to optimize the personal approach, it is important to continue making parallel advances in medical imaging technologies and to pay close attention to aspects such as standardization and quality control, so as to obtain completely safe products for the patients. The requirements for these products should be similar to those imposed on mass-produced parts by multinational companies, and the use of final rapid-prototyped parts and devices should not be limited simply because they are not mass produced.

The use of customized implants occurs only in exceptional cases, almost always in the context of research projects, as limitations imposed by the costs and time involved usually mean that customized prostheses or implants are unable to compete with standard mass-produced alternatives. Novel approaches enabled by recent rapid prototyping and manufacturing technologies, which are enhancing the production of end products with properties similar to or better than those obtained using traditional alternatives, can greatly promote these types of medical applications.

\subsection{Direct Manufacture of Implantable Devices for Soft-Tissue Replacement}

To date, most cases in which rapid prototyping technologies have been applied successfully to bioengineering in combination with information from medical images have been preoperative studies, surgical operation planning, and the development of implants for bone reconstruction. The difference in density between bone and the soft surrounding tissues means that bones are clearly visible with all types of medical imaging technologies. For that reason, software packages that convert information from medical images into CAD files with detailed information about the geometries of organs and tissues are especially effective when replicating the morphology of bones. On the basis of these virtual replicas, designing implants that replace or adapt to the bones under study is easy.

However, soft body tissues and structures have densities similar to those of the surrounding blood and body fluids, meaning that the automatic transition from images to CAD files, with the required geometries of interest, becomes complicated. In many cases, this transition requires step-by-step design interventions that increase the extent and cost of the design process.

Nevertheless, improvements in imaging systems and in design software based on information from medical images have led to promising experiments related to the development of implants adapted to soft tissues for interventional cardiology (24) and facial reconstruction (25). The latter includes the customized development of ear (26) and nose (27) replicas for cosmetic procedures that temporarily compensate for injuries caused by accidents or for previous tumor-removal surgery. Future improvements are especially linked to advances in technologies and procedures described in Section 2.5.

\subsection{Direct Manufacture of Orthotic Devices for Performance Enhancement}

Some of the earliest applications of rapid prototyping in bioengineering were in the fields of ergonomics and orthotics. These applications included the development of individualized devices 
and consumer products that were designed ad hoc, taking into account the anatomy of patients with reduced mobility. As these customizations concern nonimplantable devices (e.g., toys, kitchen utensils, orthoses), they involve far less risk to patients; therefore, they require fewer controls than those required by implantable devices before being placed on the market.

Moreover, when designing and manufacturing prototypes for nonimplantable ergonomic devices, there is no need to use medical imaging technologies such as NMR and CT, which are expensive and sometimes difficult to access. Instead, researchers can use more conventional 3D scans of the patient's anatomy, normally on the basis of optical processes such as laser measurement and digitalization from photographs. Anthropometric measurements by contact devices may also be useful for getting an idea of the geometries of interest, to which the ergonomic designs have to adapt. These types of measurements simplify and lower the cost of the design process, as no specific software to manage information from medical images is needed.

There are interesting examples of customized seats for toy cars and quads designed for children with major back problems and even with reduced mobility. A noteworthy example is Europe's Flagship R\&D Project for Rapid Manufacturing: Custom-Fit, which involves more than 30 organizations. In this project, toy cars and quads were customized for children with anatomical problems through the incorporation of personalized rapid-prototyped seats, adjustments, and safety measurements to enhance the toys' overall security and comfort $(28,29)$. These customizations can serve as a complement to other ad hoc devices that result from technological advances in mobility and adaptation to the environment. Such devices already incorporate assistance technologies such as GPS, sensor networks, and augmented reality (30).

Also important, in relation to customized products, is the development of orthoses, such as splints and insoles $(31,32)$ and femoral adaptation frames for prosthetic tibia that offer improved functionality and comfort for patients with amputations (33). Products of this nature are also starting to benefit from the possibility of incorporating monitoring systems to diagnose certain diseases or to study the evolution of injuries, as also occurs with other prosthetic devices (34).

\subsection{Direct Manufacture of Biodevices Based on Intelligent Materials}

In recent decades, numerous active materials have emerged in parallel with rapid prototyping technologies. These multifunctional, "intelligent" or "smart" materials are capable of responding, in a reversible and controllable manner, to various external physical or chemical stimuli by modifying some of their properties. Because of their sensitivity and performance, these materials can be used to develop sensors, actuators, and multifunctional systems-also known as intelligent systems - that have numerous applications in architecture, information and communication technologies, aeronautics, biomedicine, automation and machinery, and the development of consumer items.

The advantages of integrating multiple functions into one system include reductions in sizes and costs of final devices, which also help increase the size of production series and related overall efficiency. These active materials may play a decisive role in future applications, as they combine electrical, thermal, chemical, optical, magnetic, and mechanical magnitudes. These materials occur in various forms - inorganic, metallic and organic, natural or synthetic — and are sensitive to a wide variety of physical and chemical phenomena (35).

Studies have been carried out on the application of rapid prototyping technologies to promote and assist the integration of smart materials in complex devices. This research has focused mostly on electroactive polymers (36) and shape-memory polymers, which researchers have attempted to combine with other smart materials (e.g., Peltier elements, conductive textiles) to facilitate their 
activation process $(37,38)$. Rapid prototyping can be directly applied to the integration of many types of smart materials in multifunctional devices and can greatly assist the production of more compact and versatile systems.

Some studies have described specific developments in "intelligent" or active prostheses that are capable of controlled responses to various stimuli and, therefore, have the potential to replace conventional passive prostheses. Several projects have focused on the development of prosthetic hands that allow for controlled finger movement $(39,40)$ and on the improvement of the capabilities of anthropomorphic robots (41).

We should also mention research relating to the development of smart scaffolds for tissue engineering, with capabilities such as the controlled delivery of drugs or progressive biodegradation. This research seeks to optimize certain developments in the field of tissue engineering, which we discuss in the following section (42).

\subsection{Biodevices for Tissue Engineering}

Tissue engineering combines biological and engineering expertise to provide artificially developed substitutes for tissues and organs, hence promoting repair and replacement therapies. A key element involved in tissue engineering processes is the matrix or scaffold, which serves as a substrate or framework for cell growth, aggregation, and tissue development (43). These scaffolds must be porous to allow cell migration during the colonization process and to allow the transport of nutrients and waste to and from cells. Moreover, cells are able to sense their microenvironment and the substrate texture on which they lie by changing their morphology, their cytoskeleton configuration, and their intra- and extracellular signaling. For this reason, efforts are increasingly being focused on design and manufacturing technologies able to generate and modify the structure and surface of biomaterials $(44,45)$.

Aspects such as porosity, pore size, and surface microtexture promote cell adherence, migration, and proliferation within the scaffold, for subsequent differentiation into relevant cell types. Thus, the scaffold plays a fundamental role in most tissue engineering strategies as its properties can greatly influence the overall success of new tissue formation. Therefore, the controlled fabrication of scaffold structures is becoming increasingly important in these modern approaches to regenerative medicine $(46,47)$.

Not only is the structure of the scaffold important, but modifications to its surface may also have a significant effect (48-50). Some in vitro studies have focused on the influence of pore size and surface microtexture on cell growth and aggregation (51, 52). However, these studies did not use a rapid prototyping approach, which has proven useful in introducing systematic variations for methodical validations. Abrasives or corrosive chemicals are generally used to obtain such microtextures and microstructures, and precisely controlling the final characteristics and the related biological aspects can be difficult. Recently, hydrogel porogens have been proposed as an alternative to overcome certain limitations in conventional scaffold fabrication techniques, although additional in vitro validation is still pending (53).

Rapid prototyping, in combination with medical imaging and CAD-CAE software, is proving to be a powerful tool in the design and manufacture of scaffolds because it allows complex geometries to be produced, usually in an additive way, using a wide range of materials (54). Several scaffolds with controlled microstructures have already been manufactured using different rapid prototyping technologies such as selective laser sintering (55), layered hydrospinning (56), laser stereolithography (57), digital light projection (58), and two-photon lithography (59) and different materials such as hydrogels (60), gelatin (47), titanium alloys (61), some photopolymers (62), and ceramics (63). 


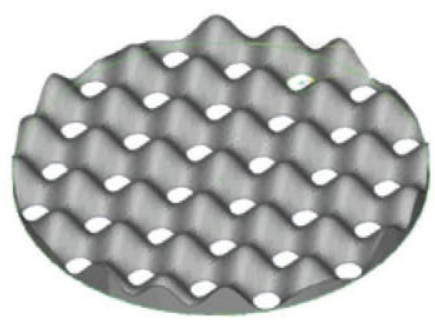

Scaffold design produced with help of CAD software

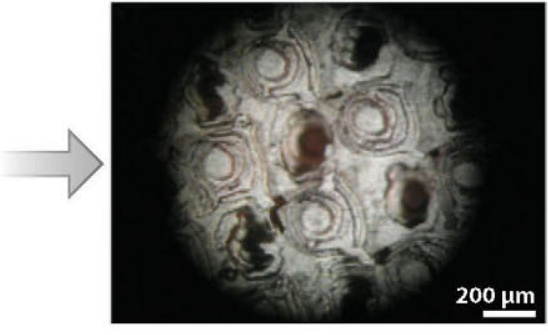

Rapid prototype for cell culture manufactured, directly from CAD file, in an additive way

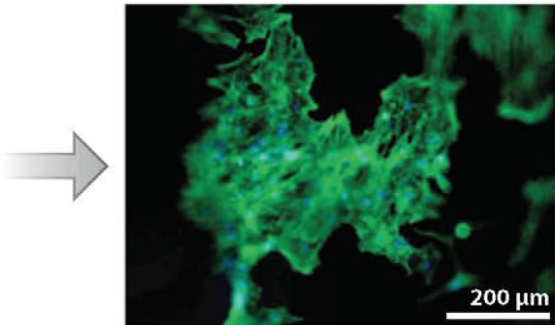

Cell culture atop rapidprototyped scaffold for subsequent in vitro/in vivo studies

Figure 4

Schematic description of tissue engineering using rapid-prototyped scaffolds: from computer-aided design (CAD) model to cell culture for further in vitro and in vivo studies. Additional details regarding the design, manufacturing, and cell culture processes can be found in Reference 66.

However, in vitro validation of such rapid-prototyped scaffolds is less common, as most processes and materials cannot be combined in a way that promotes biocompatibility without generating toxic components. Nevertheless, some highly interesting research has already been published (63). Recent advances in the field of biomedical polymers (64), together with exhaustive research on the development of 3D bioplotters (e.g., envisionTEC GmbH of Gladbeck, Germany) and 3D cell printing (65), will bring new opportunities to this area. However, access to such materials and technologies is not always possible, as some are still under development.

Figure 4 shows the conventional stages followed when rapid prototyping technologies are used to promote tissue engineering studies. The process begins with a CAD model of the scaffold's geometry for subsequent additive manufacturing and cell culture. Then, in vitro trials are carried out to accomplish cell differentiation or pharmaceutical assessment. Finally, in vivo trials in animal models are conducted to validate novel therapeutic approaches and even final implantation. Additional details can be found elsewhere (66) and in the references mentioned above.

Tissue engineering is closely linked to new trends in biomanufacturing, as detailed in Section 2.8. Of all the application areas discussed in Section 2, tissue engineering has shown the fastest growth in the past five years in terms of the application of rapid prototyping technologies. This growth is summarized in the following section, although its great potential has already been described $(67,68)$.

\subsection{Summary of Applications}

Figures 5 and $\mathbf{6}$ show the results of a search on 1170 articles in Thomson Reuters's Web of Knowledge ${ }^{S M}$ for the applications of rapid prototyping in the biomedical engineering and health sciences. The search, carried out in January 2011, was performed using "rapid prototyping" as the search topic. The papers of interest were then refined by selecting fields related to bioengineering and biotechnology.

Rapid prototyping technologies, especially in the past two decades, have brought effective solutions to many fields of bioengineering and health sciences, including surgery, traumatology, orthopedics, dentistry, internal medicine, neurology, interventional cardiology, and cell biology, as well as many other notable examples. Where implants are concerned, the rapid prototyping technologies are already well established, and they are used to complement conventional procedures. Dentistry is a prime example, in part because dental surgery rarely represents a danger to the 


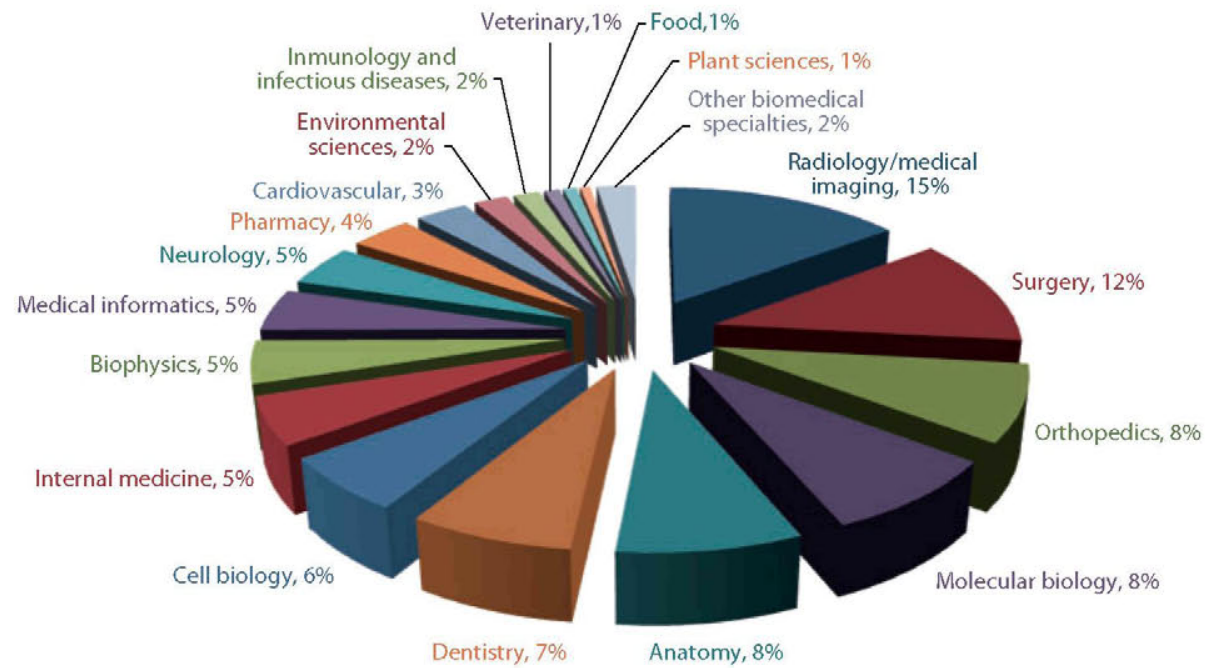

Figure 5

Applications for rapid prototyping in bioengineering, according to field. Data from Thomson Reuters's Web of Knowledge ${ }^{S M}$ database, January 2011.

patient's life. Moreover, personalized approaches in dentistry are common owing to the aesthetic importance of customized implants and to the high added value (and marketing) involved in the use of these technologies for professional dentists and aestheticians. In other fields such as tissue engineering, despite its remarkable growth over the past five years, the use of these technologies is still limited to research, and most experiments are still conducted on animal models.

The leading uses for rapid prototyping technologies are the development of models for diagnosis, the development of models for surgical planning and training, and the direct manufacture of implants for bone reconstruction, all of which account for almost $60 \%$ of applications. Approximately $14 \%$ of research relates to the development of prototypes for tissue engineering,

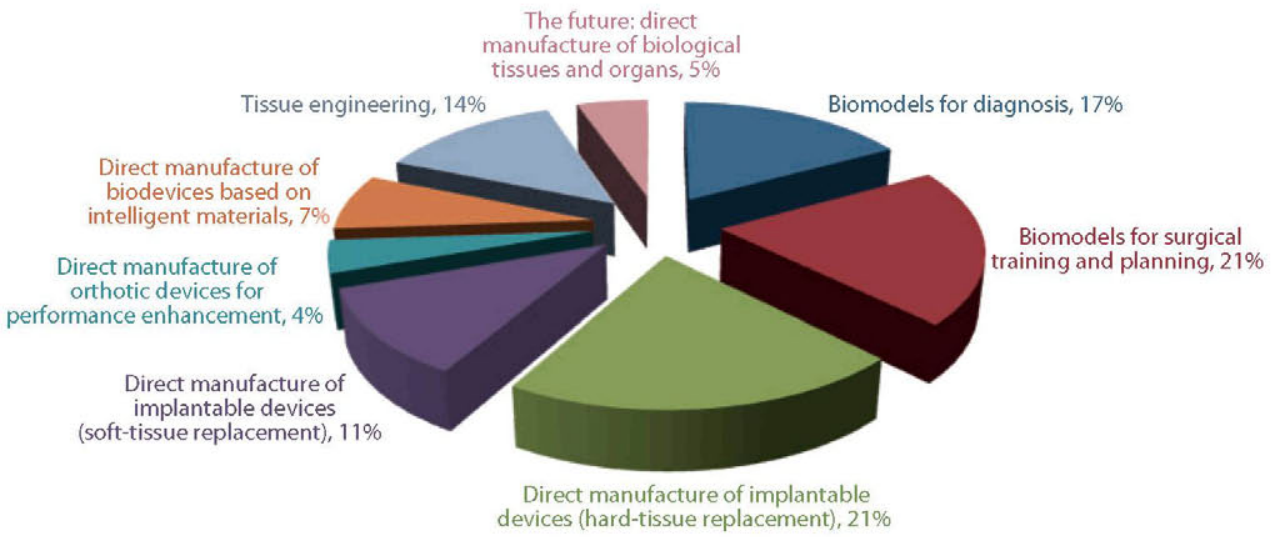

Figure 6

Applications for rapid prototyping in bioengineering, according to objective pursued. Data from Thomson Reuters's Web of Knowledge ${ }^{\mathrm{SM}}$ database, January 2011. 
although this field accounts for $40 \%$ of the scientific papers published in the past five years on the use of rapid prototyping in bioengineering; thus, tissue engineering is the most relevant field at present.

\section{SUPPORT TECHNOLOGIES}

When science and technology progress simultaneously in various disciplines, the result is a gradual blend of different areas of knowledge. These areas of knowledge influence one another, and their boundaries, once clearly identifiable, gradually dissolve, giving rise to new fields of study that require knowledge of different subjects and benefit from collaboration among researchers. As a result, researchers are increasingly working in multidisciplinary teams to carry out complex projects.

To take advantage of this gradual dissolution of boundaries between fields of knowledge, it is essential to be alert to the scientific and technological advances occurring in related fields and to analyze systematically how such advances can be mutually beneficial. Listed below are some areas in which recent advances can help greatly enhance the industrial impact of rapid prototyping technologies, especially in their application to bioengineering.

\subsection{Advances in Biomimetic Computer-Aided Design and Engineering}

Several studies have focused on the importance of surface topography and microtexture in promoting positive effects in biomedical devices, such as implantable prostheses, extracellular matrices, and scaffolds for cell and tissue growth. These microtextures have a significant influence on the osseointegration of prostheses, on cell proliferation, and on tissue growth, as cells and tissues seem to be more "comfortable" when faced with biodevices that have surface properties similar to those of original tissues.

However, the process of introducing a desired roughness on the surfaces of a human-made object is still mainly performed by machining, laser processing, or chemical attacks. In all these cases, postprocessing operations can be difficult to control, and it would be far more practical to directly impose biomimetic topographies from the design stage. Fractal models that mimic such natural surfaces can be useful for designing advanced biodevices with special surface topographies and microtextures.

Fractals are rough or fragmented geometric shapes that can be split into parts, each of which is (at least approximately) a reduced-size copy of the whole. The term fractal was coined by Benoit Mandelbrot in 1975 and derives from the Latin fractus meaning "broken" or "fractured." The term is used to describe complex self-similar geometries that are too intricate to be formulated in conventional Euclidean terms and that are usually defined with simple recursive procedures.

From the earliest studies on fractal geometry, it became clear that fractals could be used to describe the geometries, patterns, and roughness of natural objects. Although fractals are considered to be infinitely complex (owing to their recursive definitions), approximate fractals are easily found in natural objects, which usually display self-similar structure over an extended, but finite, scale. Limiting the steps applied in a recursive definition of a conventional fractal yields approximate fractals, which mimic complex natural geometries. Natural objects that are approximated by fractals include clouds, mountains, lightning bolts, coastlines, snowflakes, various vegetables, and several corporal geometries $(69,70)$.

During the past decade, attention has been increasingly given to the use of fractals in modeling, design, and simulation tasks in several areas of bioengineering. The most notable research includes modeling the behavior of microorganisms (71), modeling complex organisms and their systems 
(including human anatomy) (72), and modeling the surfaces of organs and tissues (73). These fractal models of biological objects have been combined with the capabilities of $\mathrm{CAD}$, with engineering and manufacturing software, and with the advances made in rapid prototyping technologies. The result has been the ability to generate designs and prototypes of biomedical devices capable of mimicking the surfaces of organs and tissues, thus improving the designs and in vivo performance of several prosthetic devices.

Some proposals for tissue engineering have already been analyzed, including the conversion of fractal models into .stl format for subsequent prototyping tasks, although some limitations regarding the accuracy needed to describe all the fractal features adequately still have to be overcome (57). Progress in micro- and nano-rapid prototyping will promote such detailed biomimetic approaches, as described in Sections 3.3 and 3.4.

\subsection{Imaging and Imaging-Based Design Technologies}

The first medical imaging technologies used to support the production of customized devices were NMR (74) and X-ray-based technologies, usually with CT (75). However, progress is continually being made in developing new technologies, or in increasing the accuracy of existing ones, to obtain devices with higher-quality designs that are more suitable to patients (76). Multislice CT, for example, helps minimize the effect that the movement of muscular structures (e.g., the heart) has on data collection and on customization, and it even can be applied to soft tissues (25). Recent developments in microC T allow an accuracy of a few tens of micrometers and are already providing solutions for some customized implants that require high precision $(77,78)$.

All this progress is enhanced by software that is capable of handling medical images and by the images' subsequent connection to CAD-CAE-CAM programs, which have improved significantly in recent years, particularly since the implementation of the DICOM standard (digital imaging and communications in medicine) for information exchange. Remarkable examples of this kind of software include Mimics and SimPlant ${ }^{\circledR}$ (Materialise NV) and Medco (PRISM Consulting Services). This type of software can also simulate the in situ behavior of the associated devices, generally using CAE programs that carry out calculations based on the finite element method. These calculations help researchers verify design decisions before manufacturing prototypes for testing and final validation $(79,80)$.

Figure 7 includes a general outline of the customized design process for biodevices that uses imaging technologies in combination with CAD, CAE, and CAM tools. It also shows how rapid prototyping technologies can be used to complement these processes to achieve various outcomes. The developments shown have been carried out at the Product Development Laboratory of the Universidad Politécnica de Madrid; additional information can be found in References 25 and 35 .

\subsection{Novel Micro-Rapid Prototyping Technologies for Advanced Biomaterials}

As mentioned above, conventional rapid prototyping technologies (those that have provided continued service to different industries for approximately two decades) can produce parts within a few hours out of various materials such as polymers, alloys, and ceramics, usually additively and with a $150-500-\mu \mathrm{m}$ degree of precision. However, since the beginning of the twenty-first century, significant advances have been made in developing new rapid prototyping technologies that can produce geometries with greater detail and use biomaterials such as collagen, agar, alginate, hydroxyapatite, calcium phosphate, chitin, gelatins, bioink, and biopolymers such as polycaprolactone, poly(lactic acid), poly(glycolic acid), and even spider silk. 

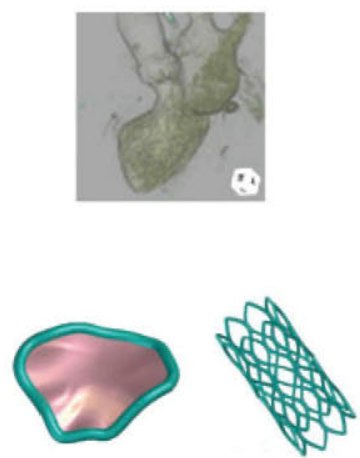

Virtual prototypes for in silico trials/ FEM simulations and design validation

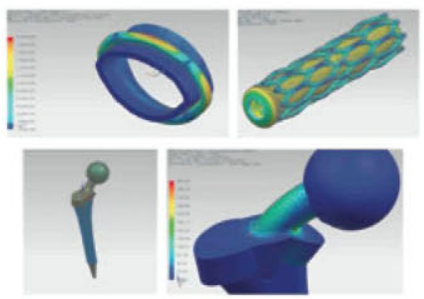

Medical imaging technologies (e.g., microCT, NMR):

Personalized information from patients

Mimics-like software, MedCAD, SimPlant ${ }^{\ominus}$ : From images to .stl format or meshed solid

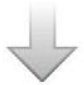

Personalized CAD 3D geometries based on the information from medical images:

Virtual implants for soft- and hard-tissue replacement
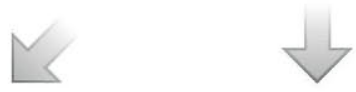

Rapid prototypes for diagnosis, surgical planning, and training
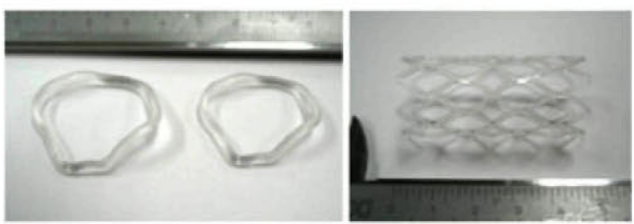
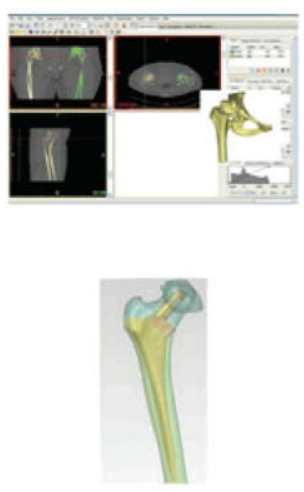

Rapid prototypes for in vivo/in vitro trials or implantation

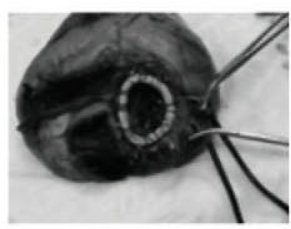

Figure 7

Overall production process of customized biodevices, combining information from medical images with the functions of rapid design and manufacturing. Examples of biodevice designs customized for soft and hard tissues include a reinforcement annuloplasty ring for a heart valve, an expandable stent, and a femoral prosthesis, along with the results of finite element method simulations and physical prototypes for surgical research and interventions. Abbreviations: CAD, computer-aided design; CT, computed tomography; FEM, finite element method; NMR, nuclear magnetic resonance; stl, standard tessellation language.

These technologies are therefore increasingly able to produce devices (whether orthotic, prosthetic, or implantable) suitable for working in close contact with biological tissues, thereby increasing the impact of these manufacturing tools in the biomedical and health sciences sectors. Early research was done in laser microstereolithography by the École Polytechnique Fédérale de Lausanne and the Laser Zentrum Hannover, although recent years have seen the emergence of many other technologies that offer sufficient precision for most applications, including those involving interactions at the cellular level (see Table 1).

\subsection{Nanomanufacturing for Interacting at a Molecular Scale}

Advances in additive microfabrication have already made it possible to interact at the cellular level in numerous processes involved in tissue engineering and related studies (e.g., the generation of microchannels to analyze cell motility or surface microtextures to promote the growth of certain tissue types). All these processes can be further optimized through the use of nanofabrication technologies, which help produce certain interactions at the molecular level and promote chemical, tribological (contact), or fluidic phenomena in combination with the highly precise rapid prototyping technologies shown in Table 1. 
Table 1 Comparison of high-precision rapid manufacturing processes

\begin{tabular}{|c|c|c|c|}
\hline Technology & Precision & Materials & $\begin{array}{l}\text { Working } \\
\text { principle }\end{array}$ \\
\hline Two-photon polymerization & Approximately $200 \mathrm{~nm}$ & Photopolymers & Additive \\
\hline Microstereolithography & $5-35 \mu \mathrm{m}$ & Photopolymers & Additive \\
\hline Digital light processing & $50 \mu \mathrm{m}$ & Photopolymers & Additive \\
\hline Bioplotters and bioprinters ${ }^{a}$ & $250-400 \mu \mathrm{m}$ & Biological materials & Additive \\
\hline Laser micromachining & $15-100 \mu \mathrm{m}$ & $\begin{array}{l}\text { Organic and } \\
\text { inorganic materials }\end{array}$ & Subtractive \\
\hline X-ray-based microfabrication & $100 \mathrm{~nm}-100 \mu \mathrm{m}$ & $\begin{array}{l}\text { Metals, plastics, glass, } \\
\text { ceramics }\end{array}$ & Subtractive \\
\hline Pressure-assisted microsyringe & $10-600 \mu \mathrm{m}$ & Biopolymers & Additive \\
\hline Robocasting & $100-1000 \mu \mathrm{m}$ & Organic ink & Additive \\
\hline Conventional 3D printers & $250-400 \mu \mathrm{m}$ & Waxes, polymers & Additive \\
\hline Conventional stereolithography & $150-300 \mu \mathrm{m}$ & Photopolymers & Additive \\
\hline $\begin{array}{l}\text { Conventional fused deposition } \\
\text { modeling }\end{array}$ & $350-500 \mu \mathrm{m}$ & $\begin{array}{l}\text { Waves, } \\
\text { thermoplastics }\end{array}$ & Additive \\
\hline Conventional CNC machining & $75-150 \mu \mathrm{m}$ & Mainly metals & Subtractive \\
\hline
\end{tabular}

${ }^{a}$ See Section 4.

Abbreviation: CNC, computer numerical control.

Living beings exhibit forms and functions at different levels, and, because rapid prototyping technologies mimic these natural multilevel structures, they can be of great help in the manufacture of microtextures. Other subtractive techniques based on chemical attacks-such as soft lithography and maskless ultraviolet photolithography, whose applications in microelectronics and bioengineering are widely known (81) - are still difficult to apply in the construction of geometries with details smaller than $500 \mathrm{~nm}$ and with 3D features. High-precision rapid prototyping, working in an additive way, helps produce more complex geometries and devices, including ad hoc microtextures and even nanotextures.

In addition, starting from a rapid-prototyped microsystem or biodevice with micrometric features, researchers can generate nanostructures through the self-assembly of molecules and thus build medical devices sensitive to specific stimuli, arrays of sensors, and optical and fluidic systems. Such devices have numerous applications in interacting with biological systems and in generating highly specific diagnoses of reactions and pathologies (82).

Progress has also been made in technologies of physical or chemical vapor deposition, especially those capable of producing diamond-like carbon, titanium dioxide or hydroxyapatite coatings. When these materials are applied to the surfaces of implantable devices, they greatly improve the devices' biocompatibility, improve their ability to resist corrosion and wear, and even allow for antibacterial properties to be incorporated through doping with metals such as silver or platinum $(83,84)$.

The use of biocompatible physical-vapor-deposition or chemical-vapor-deposition coatings in helping create cellular circuits and in allowing for interactions between devices and nerve cells has already been described (85). Their application to scaffolds for tissue engineering, produced by conventional rapid prototyping technologies such as laser stereolithography or selective laser sintering, also has the potential to improve the behavior of many polymeric and ceramic substrates $(57,66)$. 


\section{MAIN CHALLENGES AND FUTURE PROPOSALS}

\subsection{From Tissue Engineering to Biofabrication}

Important advances over the past two decades in materials science, mechanical engineering technologies, and tissue engineering methods are beginning to allow developments that exceed the traditional capacities of tissue engineering. What were once mere aspirations have now become a reality: the artificial creation of complex biological products using living cells, scaffolds, or extracellular matrices, along with the creation of biomaterials with a microstructure often defined from the design stage. The idea of biomanufacturing has become common. The purpose of all these developments is to generate tissues and organs in the laboratory that may assist in the treatment of diseases or be used in physiological and pharmacological studies (86).

Possibly the most interesting technologies and outstanding advances in this field relate to $3 \mathrm{D}$ bioprinters or bioplotters, rapid prototyping machines that work with an additive layer-by-layer manufacturing approach and use biological materials to directly produce implants or biodevices that have properties similar to those of body tissues. These bioplotter machines (such as those from envision'TEC $\mathrm{GmbH}$ ) are being systematically tested with several biomaterials (collagen, agar, alginate, hydroxyapatite, calcium phosphate, chitin, gelatin, bioinks, biopolymers) and even with food. In some cases, biofluids and hydrogels that directly incorporate the cells are injected; in other cases, a couple of printer heads are used to deposit biodegradable polymers as structural support, together with cells and nutrients, for subsequent differentiation into the desired tissues or parts of organs.

Most research conducted in the field of biomanufacturing describes processes that are clearly related to tissue engineering but aimed at achieving more complex geometries that, together with seeded cells and growth factors, will be capable of producing whole organs in the future. This is an essential objective, as there is a great need for, and short supply of, organs for transplantation; this problem, despite its great social impact, remains unsolved.

Consequently, several studies have focused on how to produce soft tissue synthetically through methods such as the reconstruction of epidermis (87), the production of muscle fibers (88), the production of artificial liver (or parts thereof) (89), and the production of tissues for tracheal reconstruction (90). Additional details on the main research trends, future challenges, and the future potential of this field can be found in other, more specific studies $(91,92)$.

\subsection{Enhanced Biological Systems}

In the not-too-distant future (some researchers even say within 15 to 20 years, although 25 to 30 years seems a better estimation), further developments in biomanufacturing and rapid prototyping and manufacturing technologies may allow for the direct printing of customized implants, probably using biological materials similar to those of the human body, in the design and manufacturing facilities attached to the operating rooms of hospitals or health centers. These developments-together with parallel advances in minimally invasive surgery, remote surgery using haptic teleoperators, intelligent implants for monitoring and diagnosing patients, and new drugs with greater specificity and fewer side effects-suggest a great number of new treatment methods and the possibility of replacing deteriorating human organs with ones made artificially, resulting in a significant increase in life expectancy.

Improving biological systems as a whole may even be possible. For example, arrays of sensors and actuators could be incorporated into the artificially produced anatomical elements to generate self-diagnostic capabilities and even self-healing abilities, possibly by applying concepts and 
design strategies that are already being used in the development of self-sensitive and self-repairing materials and structures (93).

To achieve this, it is increasingly necessary to implement multidisciplinary teams, to apply methodologies that help systematize the development of devices, and to develop new regulations that address issues of patient safety and ethics associated with these fields of study. A political commitment to fund this research, whose social benefits can be truly formidable, will be key to determining which countries play an important role in the development of this sector. Given the major social benefits to be derived from this research, it should be seen as a highly profitable investment for the future. In any case, international collaboration and the establishment of clusters of significant research will also prove crucial.

\subsection{Food, Pharmaceuticals, and Sustainable Growth}

In addition to the shortage of organs for transplantation, new biomanufacturing approaches can help solve another problem: that of a growing global population requiring an increase in food production in proportions that may become unsustainable under various economic, energetic, and industrial criteria. Bioplotters in large food production facilities that use approaches similar to those currently used in biomanufacturing may offer an alternative or complementary method to provide food for humankind. Recent years have seen applications for patents associated with systems of rapid food manufacturing that use an additive layer-by-layer approach $(94,95)$. Its implementation appears to be simpler than aforementioned developments in the field of biomanufacturing, as the manufacturing of synthetic food does not require the building of a complex network of blood vessels for vascularization.

The use of rapid prototyping technologies may also benefit the pharmaceutical industry, as they can provide new approaches to the design and microstructuring of drugs and help develop various alternatives in the ways they are supplied (96). Some research has already described the production of drugs that have specific geometries. Others describe implantable devices made through additive manufacturing that contain, either within them or on their surfaces, drugs aimed at minimizing a possible rejection by the body or the occurrence of postoperative infection $(97,98)$.

In Figure 8, we compare the novelty and interest of these new fields of application for rapid prototyping technologies by presenting the evolution of scientific papers and patents. The fields of biofabrication and organ printing, which are closely interrelated, account for approximately $80 \%$ of papers and patents. However, a marked increase in applications of rapid prototyping is related to the development of food and drugs.

\subsection{The Need for Collaboration Among Researchers}

To further boost the industrial growth of rapid prototyping technologies and, above all, to promote their application to the development of new devices in bioengineering, it is essential for universities, research centers, leading companies in the sector, and researchers to collaborate and exchange information regarding the scientific and technological progress of these methods and their applications. It is the job of teachers and researchers to draw attention to new fields of study and to emphasize the importance of working on them together in a coordinated manner, seeing other researchers as partners.

Remarkable efforts of international collaboration have been made in the field of rapid prototyping in recent decades. New advances have been disseminated by the annual report of Wohlers Associates (2), and national or international organizations have been created to work together on rapid manufacturing activities. It is also important to make these technologies more accessible and 


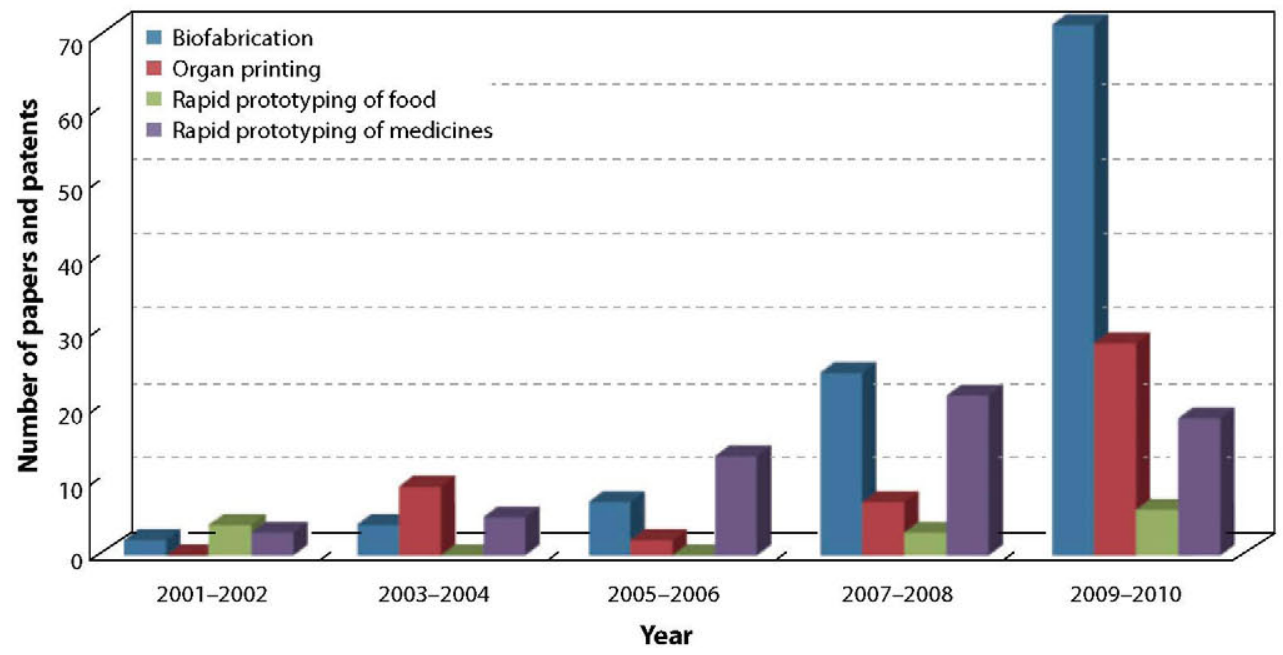

Figure 8

Evolution of the number of scientific papers and patents related to the novel use of rapid prototyping technologies in various areas of bioengineering. Data compiled from the results of searches performed on Thomson Reuters's Web of Knowledge ${ }^{S M}$ using the search terms "biofabrication," "organ printing," "rapid prototyping of food," and "rapid prototyping of medicines."

to appreciate the potential benefits of involving amateur researchers, many of whom already have "factories in a box" or "fabbers" (rapid prototyping machines) in their own homes.

Existing university courses are gradually starting to incorporate coverage of rapid prototyping and manufacturing technologies, and master's programs are starting to offer more specific courses focusing on the technologies' main aspects and implications. Most of the courses addressing this topic are courses in anatomy or general surgery that are held in medical facilities, where biomodels are used to help analyze the morphology and relative positions of internal organs in the human body $(99,100)$. Product design courses also include activities related to rapid prototyping and manufacturing technologies, and these activities have helped improve the results of problem- or project-based learning experiences; specifically, the students can see the results of their designs, detect errors and possible improvements by physically interacting with them, and carry out redesign activities accordingly (101). It is indeed important to continue working in that direction.

\section{CONCLUSIONS}

In the past two decades, rapid prototyping and manufacturing technologies have brought about significant changes to conventional methods of design and product development and have provided personalized responses to market demands often characterized by their exclusivity. They have become an invaluable aid to engineers and designers of new products, who use them in their design decisions at every stage of the development process, considerably reducing the time and cost involved.

In the fields of bioengineering and health sciences, these technologies are already providing alternative solutions to conventional diagnostic, surgical, and therapeutic procedures. This review has described numerous applications in various different fields and industries related to medicine, surgery and dentistry, biology, and pharmacy. The way in which rapid prototyping technologies 
are applied to these fields also varies, with activities ranging from prototypes and biological models for multiple studies to the customized manufacture of all types of implants.

These technologies are also likely to contribute to major future advances in the health sciences, especially helping with the creation of optimized biological systems in the fields of tissue engineering and biomanufacturing. Achieving these objectives requires collaboration among researchers from different fields, the allocation of funding, the implementation of management strategies designed specifically for this type of research, and a readiness to take advantage of important technological advances in other sectors. These efforts will undoubtedly help involve rapid prototyping and manufacturing in even more areas of study related to bioengineering.

\section{SUMMARY POIN'TS}

1. Rapid prototyping and manufacturing technologies have changed the traditional product development process, as they allow prototypes and even final parts to be produced in a wide range of materials and with remarkable precision in just a couple of hours.

2. In the biomedical field, rapid prototyping has already shown its potential for generating models for diagnosis and surgical planning, personalized prostheses for hard- and softtissue replacement, ad hoc orthotic devices, and scaffolds for tissue engineering.

3. The combined use of medical imaging tools, CAD and CAE software, and rapid prototyping technologies enables the cost-effective and time-efficient development of personalized biomedical devices.

4. Tissue engineering is starting to benefit enormously from these advanced manufacturing technologies, owing to the advantages they provide in the manufacturing of complex, biomimetic porous $3 \mathrm{D}$ scaffolds and support structures for cell culture.

\section{FUTURE ISSUES}

1. Research efforts in the development of new rapid prototyping technologies that have improved precision and the capability to manufacture a wider set of biomaterials will open new horizons in several fields of bioengineering.

2. Given the possibilities and special characteristics enabled by rapid prototyping, knowledge systematization and gradual standardization to support the complex stages involved in the design process of novel products are necessary for increasing efficiency.

3. The promotion of multidisciplinary teams and research centers is essential for increasing the impact of these technologies and for exploring novel applications in different fields of biomedical and health sciences.

4. The development of training courses covering the basics and applications of rapid prototyping, especially in biomedical engineering degrees and using project-based learning approaches, is relevant for the expansion of these technologies.

5. Once the present challenges are faced, the hospitals of the future will surely benefit from more multidisciplinary laboratories with advanced design and rapid prototyping facilities that allow researchers to produce personalized therapeutic devices for enhanced treatments. 


\section{DISCLOSURE STATEMENT}

The authors are not aware of any affiliations, memberships, funding, or financial holdings that might be perceived as affecting the objectivity of this review.

\section{ACKNOWLEDGMENTS}

This work was supported in part by the Spanish Ministry of Science and Innovation through the Singular Strategic Research Project IBE-Rapid Manufacturing (PSE-020000-2009-1), a project led by the Ascamm Technology Center in collaboration with several industrial partners and universities, including the Universidad Politécnica de Madrid. We thank Prof. Predestinación García Ruíz from the Department of Molecular Biology at the Universidad Autónoma de Madrid for her advice and support in tasks related to the study of rapid prototypes for tissue engineering applications. We also thank Dr. José Luis Endrino from the Department of Surfaces and Coatings at the Materials Science Institute of Madrid for his support in research activities related to optimizing the biocompatibility of rapid prototypes.

\section{LITERATURE CITED}

1. Kucklick TR. 2006. The Medical Device R\&D Handbook. Boca Raton, FL: CRC/Taylor \& Francis

2. Wohlers T. 2010. Wohlers Report 2010: Additive Manufacturing State of the Industry. Fort Collins, CO: Wohlers Assoc.

3. Court LE, Seco J, Lu XQ, Ebe K, Mayo C, et al. 2010. Use of a realistic breathing lung phantom to evaluate dose delivery errors. Med. Phys. 37(11):5850-57

4. Erdelt KJ, Lamper T. 2010. Development of a device to simulate tooth mobility. Biomed. Tech. 55(5):27378

5. Nie W, Zhang J, Wang Z, Wang C, Liu Z. 2008. Rapid prototyping manufacture of human scoliosis based on laminated object technology. Sheng Wu Yi Xue Gong Cheng Xue Za Zhi 25(6):1260-63 (In Chinese)

6. Werner H, dos Santos JR, Fontes R, Gasparetto EL, Daltro PA, et al. 2008. The use of rapid prototyping didactic models in the study of fetal malformations. Ultrasound Obstet. Gynecol. 32(7):955-56

7. Bhagat AAS, Jothimuthu P, Papautsky I. 2007. Photodefinable polydimethylsiloxane (PDMS) for rapid lab-on-a-chip prototyping. Lab Chip 7(9):1192-97

8. Kaigala GV, Ho S, Penterman R, Backhouse CJ. 2007. Rapid prototyping of microfluidic devices with a wax printer. Lab Chip 7(3):384-87

9. Ke K, Hasselbrink EF, Hunt AJ. 2005. Rapid prototyped three-dimensional nanofluidic channel networks in glass substrates. Anal. Chem. 77(16):5085-88

10. Bakhos D, Velut S, Robier A, Al zahrani M, Lescanne E. 2010. Three-dimensional modeling of the temporal bone for surgical training. Otol. Neurotol. 31(2):328-34

11. Ciocca L, De Crescenzio F, Fantini M, Scotti R. 2009. CAD/CAM and rapid prototyped scaffold construction for bone regenerative medicine and surgical transfer of virtual planning: a pilot study. Comput. Med. Imaging Graph. 33(1):58-62

12. Oliveira M, Hussain NS, Dias AG, Lopes MA, Azevedo L, et al. 2008. 3-D biomodelling technology for maxillofacial reconstruction. Mater. Sci. Eng. C 28(8):1347-51

13. Leiggener C, Messo E, Thor A, Zeilhofer HF, Hirsch JM. 2009. A selective laser sintering guide for transferring a virtual plan to real time surgery in composite mandibular reconstruction with free fibula osseous flaps. Int. F. Oral Maxillofac. Surg. 38(2):187-92

14. Sohmura T, Lida S, Aikawa T, Kogo M, Iguchi Y, et al. 2009. Simulation of osteotomy and support for surgery using VR haptic device. Stud. Health Technol. Inform. 142:331-36

15. Jacobs S, Grunert R, Mohr FW, Falk V. 2008. 3D imaging of cardiac structures using 3D heart models for planning in heart surgery: a preliminary study. Interact. Cardiovasc. Thorac. Surg. 7(1):6-9 
16. Jürgens P, Krol Z, Zeilhofer HF, Beinemann J, Schicho K, et al. 2009. Computer simulation and rapid prototyping for the reconstruction of the mandible. 7. Oral Maxillofac. Surg. 67(10):2167-70

17. Hananouchi T, Saito M, Koyama T, Hagio K, Murase T, et al. 2009. Tailor-made surgical guide based on rapid prototyping technique for cup insertion in total hip. Int. 7. Med. Robot. Comput. Assist. Surg. $5(2): 164-69$

18. Kim SH, Choi YS, Hwang EH, Chung KR, Kook YA, Nelson G. 2007. Surgical positioning of orthodontic mini-implants with guides fabricated on models replicated with cone-beam computed tomography. Am. 7. Orthod. Dentofacial Orthop. 131(4):82-89

19. Warren FM, Balachandran R, Fitzpatrick JM, Labadie RF. 2007. Percutaneous cochlear access using bone-mounted, customized drill guides: demonstration of concept in vitro. Otol. Neurotol. 28(3):325-29

20. Gittard SD, Narayan RJ, Lusk J, Morel P, Stockmans F, et al. 2009. Rapid prototyping of scaphoid and lunate bones. Biotechnol. 7. 4(1):129-34

21. Kocacikli M, Korkmaz FM, Yazicioglu H, Yalug S. 2010. Fabricating toe prostheses using 3D modeling technique: case report. Turk. Klin. F. Med. Sci. 30(5):1750-55 (In Turkish)

22. Goh RCW, Chang CN, Lin CL, Lo LJ. 2010. Customised fabricated implants after previous failed cranioplasty. 7. Plast. Reconstr. Aesthet. Surg. 63(9):1479-84

23. Probst FA, Hutmacher DW, Müller DF, Machens HG, Schantz JT. 2010. Calvarial reconstruction by customized bioactive implant. Handchir. Mikrochir. Plast. Chir. 42(6):369-73 (In German)

24. Jiang HJ, Campbell G, Xi FF. 2005. Measurement and reconstruction of the leaflet geometry for a pericardial artificial heart valve. Med. Eng. Phys. 27(2):175-80

25. Díaz Lantada A, Valle-Fernández RD, Lafont Morgado P, Muñoz-García J, Muñoz-Sanz JL, et al. 2010. Development of personalized annuloplasty rings: combination of CT images and CAD-CAM tools. Ann. Biomed. Eng. 38(2):280-90

26. Al Mardini M, Ercoli C, Graser GN. 2005. A technique to produce a mirror-image wax pattern of an ear using rapid prototyping. F. Prosthet. Dent. 94:195-98

27. Ciocca L, Bacci G, Mingucci R, Scotti R. 2009. CAD-CAM construction of a provisional nasal prosthesis after ablative tumour surgery of the nose: a pilot case report. Eur. 7. Cancer Care 18(1):97-101

28. Gerrits A, Jones CL, Valero R, Dolinsek S. 2006. A concept of manufacturing system enabling the creation of custom-fit products. Presented at Int. Res./Expert Conf. Trends Dev. Mach. Assoc. Technol., 10th, Lloret de Mar, Spain

29. Pandremenos J, Chrussolouris G. 2009. Modular product design and customisation. Presented at CIRP Design Conf., March 30-31, Cranfield, Bedfordshire, U.K.

30. Ceres R, Pons JL, Calderón L, Jiménez AR, Azevedo L. 2005. A robotic vehicle for disabled children. IEEE Eng. Med. Biol. Mag. 24:56-63

31. Sun SP, Chou YJ, Sue CC. 2009. Classification and mass production technique for three-quarter shoe insoles using non-weight-bearing plantar shapes. Appl. Ergon. 40(4):630-35

32. Huang CN, Lee MY, Chang CC. 2011. Computer-aided design and manufacturing of customized insoles. IEEE Comput. Graph. Appl. 31(2):74-79

33. Colombo G, Filippi S, Rizzi C, Rotini F. 2010. A new design paradigm for the development of custom-fit soft sockets for lower limb prostheses. Comput. Ind. 61(6):513-23

34. Inmann A, Haugland M. 2004. Implementation of natural sensory feedback in a portable control system for a hand grasp neuroprosthesis. Med. Eng. Phys. 26(6):449-58

35. Díaz Lantada A. 2009. Metodología para el desarrollo de dispositivos médicos basados en polímeros activos como sensores y actuadores. PhD thesis. Univ. Politéc. Madrid. 303 pp.

36. Bar-Cohen Y. 2004. Electroactive Polymer (EAP) Actuators as Artificial Muscles: Reality, Potential and Challenges. Bellingham, WA: SPIE. 2nd ed.

37. Díaz Lantada A, Lafont Morgado P, Muñoz Sanz JL, Muñoz-García J, Muñoz-Guijosa JM, Echávarri Otero J. 2010. Intelligent structures based on the improved activation of shape memory polymers using Peltier cells. Smart Mater. Struct. 19(5):055022

38. Díaz Lantada A, Lafont Morgado P, Muñoz-García J, Echavarri J, Muñoz-Sanz JL, Muñoz-Guijosa JM. 2010. Intelligent expandable structures based on the improved activation of shape memory polymers. Presented at Biodevices 2010, 3rd Int. Conf. Biomed. Electron. Devices, Valencia, Spain 
39. De Laurentis KJ, Mavroidis C. 2002. Mechanical design of a shape memory alloy actuated prosthetic hand. Technol. Health Care 10(2):91-106

40. Andrianesis K, Tzes A. 2008. Design of an anthropomorphic prosthetic hand driven by shape memory alloy actuators. Proc. IEEE RAS/EMBS Int. Conf. Biomed. Robot. Biomechatron., 2nd (BioRob 2008), Scottsdale, Ariz., Oct. 19-22, pp. 517-22. Piscataway, NJ: IEEE

41. Cutkosky MR, Kim S. 2009. Design and fabrication of multi-material structures for bioinspired robots. Pbilos. Trans. R. Soc. Lond. Ser. A 367(1894):1799-813

42. Moroni L, de Wijn JR, van Blitterswijk CA. 2008. Integrating novel technologies to fabricate smart scaffolds. 7. Biomater. Sci. Polym. Ed. 19(5):543-72

43. Langer R, Vacanti JP. 1993. Tissue engineering. Science 260:920-26

44. Thomas WE, Discher DE, Shastri VP. 2010. Mechanical regulation of cells by materials and tissues. MRS Bull. 35:578-83

45. Buxboim A, Discher DE. 2010. Stem cells feel the difference. Nat. Methods 7(9):695-97

46. Bartolo PJS, Almeida H, Laoui T. 2009. Rapid prototyping and manufacturing for tissue engineering scaffolds. Int. 7. Comput. Appl. Technol. 36(1):1-9

47. Tan JY, Chua CK, Leong KF. 2010. Indirect fabrication of gelatin scaffolds using rapid prototyping technology. Virtual Phys. Prototyp. 5(1):45-53

48. Martín-Palma RJ, Manso M, Pérez-Rigueiro J, García-Ruiz JP, Martínez-Duart JM. 2004. Surface biofunctionalization of materials by amine groups. $\mathcal{F}$. Mater. Res. 19(8):2415-20

49. Hernando Pérez M, Muñoz-Noval A, Rodríguez Navas C, Manso Silvan M, Torres-Costa V, et al. 2008. Surface modification, characterization and biofunctionality of pegylated titanate films obtained by the sol-gel method. Surf. Interface Anal. 40:205-9

50. Formosa F, Sánchez-Vaquero V, Rodríguez-Navas C, Muñoz-Noval A, Tejera-Sanchez N, et al. 2010. Evaluation of plasma modified polycaprolactone honeycomb scaffolds by human mesenchymal stem cells cultured in vitamin D differentiation medium. Plasma Process. Polym. 7:794-801

51. Moroni L, Habibovic P, Mooney DJ, van Blitterswijk CA. 2010. Functional tissue engineering through biofunctional macromolecules and surface design. MRS Bull. 35:584-90

52. Gómez Ribelles JL, Monleón Pradas M, García Gómez R, Forriol F, Sancho-Tello M, Carda C. 2010. The role of three-dimensional scaffolds in the regeneration of joint cartilage. Presented at Biodevices 2010, $3 \mathrm{rd}$ Int. Conf. Biomed. Electron. Devices, Valencia, Spain

53. Kim J, Yamzeski J, Lu L. 2009. Three-dimensional porous biodegradable polymeric scaffolds fabricated with biodegradable hydrogel processes. Tissue Eng. Pant C Metbods 15(4):583-94

54. Li MG, Tian XY, Chen XB. 2009. A brief review of dispensing-based rapid prototyping techniques in tissue scaffold fabrication: role of modeling on scaffold properties prediction. Biofabrication 1:032001

55. Lohfeld S, Tyndyk MA, Cahill S, Flaherty N, Barron V, McHugh PE. 2010. A method to fabricate small features on scaffolds for tissue engineering via selective laser sintering. 7. Biomed. Sci. Eng. 3:138-47

56. Tzezana R, Zussman E, Levenberg S. 2008. A layered ultra-porous scaffold for tissue engineering, created via a hydrospinning method. Tissue Eng. Part C Methods 14(4):281-88

57. Díaz Lantada A, Mosquera A, Endrino JL, Lafont Morgado P. 2010. Design and rapid prototyping of DLC coated fractal surfaces for tissue engineering applications. 7. Phys. Conf. Ser. 252:012003

58. Stampfl J, Fouad H, Seidler S, Liska R, Schwanger F, et al. 2004. Fabrication and moulding of cellular materials by rapid prototyping. Int. 7. Mater. Prod. Technol. 21(4):285-96

59. Infür R, Pucher N, Heller C, Lichtenegger H, Liska R, et al. 2007. Functional polymers by two-photon 3D lithography. Appl. Surf. Sci. 254:836-40

60. Maher PS, Keatch RP, Donnelly K, Paxton JZ. 2009. Formed 3D bioscaffolds via rapid prototyping technology. Proc. Eur. Conf. Int. Fed. Med. Biol. Eng., 4th, Antwerp, Belg., Nov. 23-27, 2008, 22(17):22004. Berlin: Springer

61. Warnke PH, Douglas T, Wollny P, Sherry E, Steiner M, et al. 2009. Rapid prototyping: porous titanium alloy scaffolds produced by selective laser melting for bone tissue engineering. Tissue Eng. Part C Methods $15(2): 115-24$

62. Stampfl J, Baudis S, Heller C, Liska R, Neumeister A, et al. 2008. Photopolymers with tunable mechanical properties processed by laser-based high-resolution stereolithography. 7. Micromech. Microeng. 18:125014 
63. Manjubala I, Woesz A, Pilz C, Rumpler M, Fratzl-Zelman N, et al. 2005. Biomimetic mineral-organic composite scaffolds with controlled internal architecture. 7. Mater. Sci. Mater. Med. 16:1111-19

64. Jung F, Wischke C, Lendlein A. 2010. Degradable, multifunctional cardiovascular implants: challenges and hurdles. MRS Bull. 35:607-13

65. Gruene M, Deiwick A, Koch L, Schlie S, Unger C, et al. 2011. Laser printing of stem cells for biofabrication of scaffold-free autologous grafts. Tissue Eng. Part C Methods 17:1-36

66. Díaz Lantada A, Endrino JL, Sánchez-Vaquero V, Mosquera A, Lafont Morgado P, García-Ruíz JP. 2012. Tissue engineering using novel rapid prototyped diamond-like carbon coated scaffolds. Plasma Process. Polym. 9:98-107

67. Yeong WY, Chua CK, Leong KF, Chandrasekaran M. 2004. Rapid prototyping in tissue engineering: challenges and potential. Trends Biotechnol. 22(12):643-52

68. Masood SH, Singh JP, Morsi Y. 2005. The design and manufacturing of porous scaffolds for tissue engineering using rapid prototyping. Int. 7. Adv. Manuf. Technol. 27:415-20

69. Mandelbrot BB. 1982. The Fractal Geometry of Nature. New York: W.H. Freeman

70. Falconer K. 2003. Fractal Geometry: Mathematical Foundations and Applications. Chichester, UK: Wiley. 2nd ed.

71. Tsyganov MA, Kresteva IB, Aslanidi GV, Alsanidi KB, Deev A, Ivanitsky GR. 2007. The mechanisms of fractal-like structure formation by bacterial populations. 7. Biol. Phys. 25:165-76

72. Lin DW, Johnson S, Hunt CA. 2004. Modeling liver physiology: combining fractals, imaging and animation. Proc. Annu. Int. Conf. IEEE Eng. Med. Biol. Soc., 26th, San Francisco, Sept. 1-5, pp. 3120-23. Piscataway, NJ: IEEE

73. Longini S, Sartori M. 2010. Fractal geometry of nature (bone) may inspire medical devices shape. Nature Precedings. http://hdl.handle.net/10101/npre.2010.4512.1

74. Yedavalli RV, Loth F, Yardimci A, Pritchard WF, Oshinski JN et al. 2001. Construction of a physical model of the human carotid artery based upon in vivo magnetic resonance images. F. Biomech. Eng. 123(4):372-76

75. Maheshwaraa NU, Arumaikkannu G, Gowri S. 2008. Three-dimensional reconstruction and rapid prototyping of femur bone using multiple digital X-rays. 7. Med. Eng. Technol. 32(1):30-39

76. Lee MY, Chang CC, Ku YC. 2008. New layer-based imaging and rapid prototyping techniques for computer-aided design and manufacture of custom dental restoration. F. Med. Eng. Technol. 32(1):83-90

77. Guo X, Liu X, Wang X, Tian F, Liu F, et al. 2010. A combined fluorescence and microcomputed tomography system for small animal imaging. IEEE Trans. Biomed. Eng. 58:2876-83

78. Ritman EL. 2011. Current status of developments and applications of micro-CT. Annu. Rev. Biomed. Eng. 13:531-52

79. Woo DG, Lee TW, Ko CY, Kim HS, Won YY. 2006. Biomechanical tests of osteoporotic vertebral trabecular bone using finite element analysis based on micro-CT. Proc. Int. Conf. Biomed. Pharm. Eng., Singapore, Dec. 11-14, pp. 231-36. Piscataway, NJ: IEEE

80. Magne P. 2007. Efficient 3D finite element analysis of dental restorative procedures using micro-CT data. Dental Mater. 23(5):539-48

81. Whitesides GM, Ostuni E, Takayama S, Jiang X, Ingber DE. 2001. Soft lithography in biology and biochemistry. Anmu. Rev. Biomed. Eng. 3:335-73

82. Fan H, Lu Y, Stump A, Reed ST, Baer T, et al. 2000. Rapid prototyping of patterned functional nanostructures. Nature 405:56-60

83. Salgueiredo E, Vila M, Silva MA, Lopes MA, Santos JP, et al. 2008. Biocompatibility evaluation of DLC-coated $\mathrm{Si}_{3} \mathrm{~N}_{4}$ substrates for biomedical applications. Diam. Relat. Mater. 17(4-5):878-84

84. Endrino JL, Escobar Galindo R, Zhang H, Allen M, Gago R, et al. 2008. Structure and properties of silver-containing a-C(H) films deposited by plasma immersion ion implantation. Surf. Coat. Technol. 202(15):3675-80

85. Brown IG, Bjornstad KA, Blakely EA, Galvin JE, Monteiro OR, Sangyuenyongpipat S. 2003. Growth of large patterned arrays of neurons using plasma methods. Plasma Phys. Control. Fusion 45:547-52

86. Mironov V, Trusk T, Kasyanov V, Little S, Swaja R, Markwald R. 2009. Biofabrication: a 21st century manufacturing paradigm. Biofabrication 1(2):022001 
87. Staudenmaier R, Hoang NT, Mandlik V, Schurr C, Burghartz M, et al. 2010. Customized tissue engineering for ear reconstruction. Adv. Otorbinolaryngol. 68:120-31

88. Bian WN, Bursac N. 2009. Engineered skeletal muscle tissue networks with controllable architecture. Biomaterials 30(7):1401-12

89. Wang XH, Yan YN, Zhang RJ. 2007. Rapid prototyping as a tool for manufacturing bioartificial livers. Trends Biotechnol. 25(11):505-13

90. Moroni L, Curti M, Welti M, Korom S, Weder W, et al. 2007. Anatomical 3D fiber-deposited scaffolds for tissue engineering: designing a neotrachea. Tissue Eng. 13:2483-93

91. Wang XH, Yan YN, Zhang RJ. 2010. Recent trends and challenges in complex organ manufacturing. Tissue Eng. Part B Rev. 16(2):189-97

92. Mironov V, Kasyanov V, Drake C, Markwald RR. 2008. Organ printing: promises and challenges. Regen. Med. 3(1):93-103

93. Ghosh SK, ed. 2009. Self-Healing Materials: Fundamentals, Design Strategies and Applications. Weinheim, Ger.: Wiley-VCH

94. Lai W, Zheng J. 2008. Method for producing three-dimensional contouring food product with rapid prototyping technology. China Patent No. 101301107-A

95. Lai W, Cheng C. 2008. Manufacturing method of three-dimensional food by rapid prototyping. US Patent No. 20080260918-A1

96. Yu DG, Zhu LM, Brandford-White CJ, Yang XL. 2008. Three-dimensional printing in pharmaceutics: promises and problems. 7. Pharm. Sci. 97(9):3666-90

97. Scheuenpflug M, Guenther D, Irlinger D, Lueth T. 2007. Microfluidic module system with piezo driven microvalve for synthesis of radiopharmaceutical products. Proc. Annu. Int. Conf. IEEE Eng. Med. Biol. Soc., 29th, Lyon, Fr., Aug. 22-26, PP. 5708-11. Piscataway, NJ: IEEE

98. Huang WD, Zheng QX, Sun WQ, Xu H, Yang X. 2007. Levofloxacin implants with predefined microstructure fabricated by three-dimensional printing technique. Int. 7. Phamm. 339(1-2):33-38

99. Knox K, Kerber CW, Singel SA, Bailey MJ, Imbesi SG. 2005. Stereolithographic vascular replicas from CT scans: choosing treatment strategies, teaching, and research from live patient scan data. $A 7 N R A m$. 7. Neuroradiol. 26(6):1428-31

100. Thomas RG, Delieu JM, John NW, Mahon M. 2008. Using rapid prototyping to complement traditional anatomical education. 7. Anat. 212(1):95

101. Díaz Lantada A, Lorenzo-Yustos H, Lafont Morgado P, Muñoz-Guijosa JM, Muñoz-Sanz JL, Echávarri Otero J. 2007. Teaching applications for rapid prototyping technologies. Int. 7. Eng. Educ. 23(2):411-18 


\section{Contents}

The Effect of Nanoparticle Size, Shape, and Surface Chemistry on Biological Systems

Alexandre Albanese, Peter S. Tang, and Warren C.W. Chan ........................ 1

Mucosal Vaccine Design and Delivery

Kim A. Woodrow, Kaila M. Bennett, and David D. Lo .............................17

Tendon Healing: Repair and Regeneration

Pramod B. Voleti, Mark R. Buckley, and Louis 7. Soslowsky .........................47

Rapid Prototyping for Biomedical Engineering: Current Capabilities

and Challenges

Andrés Diaz Lantada and Pilar Lafont Morgado ..................................73

Continuum Mixture Models of Biological Growth and Remodeling:

Past Successes and Future Opportunities

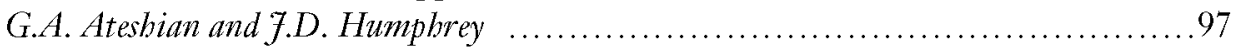

Flexible and Stretchable Electronics for Biointegrated Devices

Dae-Hyeong Kim, Roozbeb Ghaffari, Nanshu Lu, and John A. Rogers .............. 113

Sculpting Organs: Mechanical Regulation of Tissue Development

Celeste M. Nelson and Jason P. Gleghorn

Synthetic Biology: An Emerging Engineering Discipline

Allen A. Cheng and Timothy K. Lu

Nonlinear Dynamics in Cardiology

Trine Krogb-Madsen and David 7. Cbristini

Microfluidic Models of Vascular Functions

Keith H.K. Wong, Juliana M. Chan, Roger D. Kamm, and Joe Tien

Optical Nanoscopy: From Acquisition to Analysis

Travis 7. Gould, Samuel T. Hess, and Joerg Bewersdorf

Nonthermal Plasma Sterilization of Living and Nonliving Surfaces

N. De Geyter and R. Morent 255 
Robots for Use in Autism Research

Brian Scassellati, Henny Admoni, and Maja Matarić

Regulation of Cell Behavior and Tissue Patterning by Bioelectrical

Signals: Challenges and Opportunities for Biomedical Engineering

Michael Levin and Claire G. Stevenson

Intraoperative Stem Cell Therapy

Mónica Beato Coelho, Joaquim M.S. Cabral, and Jeffrey M. Karp

Optical Imaging Using Endogenous Contrast to Assess Metabolic State

Irene Georgakoudi and Kyle P. Quinn

Quantitative Imaging Methods for the Development and Validation of Brain Biomechanics Models

Philip V. Bayly, Erik H. Clayton, and Guy M. Genin

Advanced Technologies for Gastrointestinal Endoscopy

Pietro Valdastri, Massimiliano Simi, and Robert 7. Webster III

Mechanical Regulation of Nuclear Structure and Function

Rui P. Martins, John D. Finan, Farshid Guilak, and David A. Lee

\section{Indexes}

Cumulative Index of Contributing Authors, Volumes 5-14 ..................... 457

Cumulative Index of Chapter Titles, Volumes $5-14 \ldots \ldots \ldots \ldots \ldots \ldots \ldots \ldots \ldots \ldots . \ldots 61$

\section{Errata}

An online log of corrections to Annual Review of Biomedical Engineering articles may be found at http://bioeng.annualreviews.org/ 